\title{
Obituary
}

\section{MIKE BOWN}

\author{
Michael A. Carpenter* \\ Department of Earth Sciences, University of Cambridge, Downing Street, Cambridge CB2 3EQ, UK
}

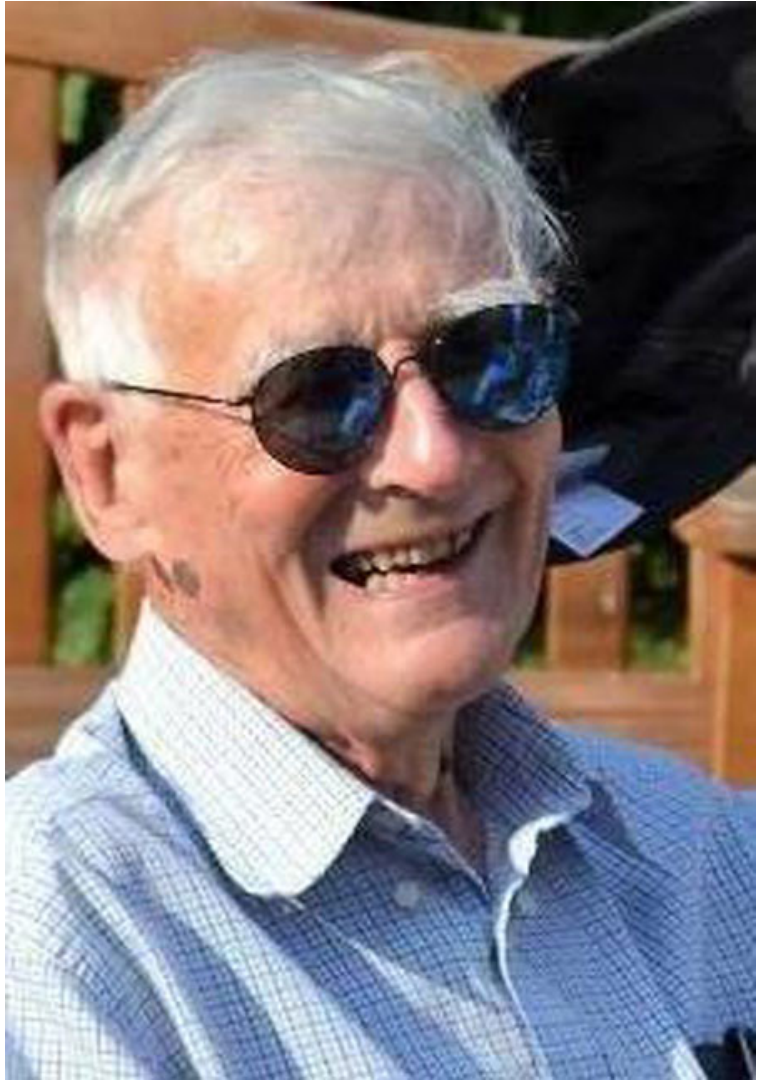

Fig. 1. Mike Bown.

Members will be sad to hear of the death of Mike Bown at the age of 93. For Cambridge alumni, Mike will be remembered with great affection as a dedicated and enthusiastic teacher of crystallography and mineralogy (Fig. 1). Those of us who had the good fortune to be on the staff with him will also remember his warmth and generosity, as well as his sharp wit and invariable good humour.

Mike was an undergraduate at Clare College, Cambridge, starting in 1946. He had been awarded a scholarship to read Natural Sciences and chose Physics in Part II. He completed two years National Service before returning to the Cavendish in 1951 for his $\mathrm{PhD}$ in the Crystallography Laboratory, which was run by W.H. Taylor. These were the last years of Sir Lawrence Bragg's

\footnotetext{
${ }^{*}$ Author for correspondence: Michael A. Carpenter, Email: mc43@cam.ac.uk Cite this article: Carpenter M.A. (2021) Obituary - MIKE BOWN. Mineralogical Magazine 85, 918-920. https://doi.org/10.1180/mgm.2021.71
}

tenure as Cavendish Professor, and still very much a pioneering time for crystal structure determination before the advent of 4-circle diffractometers and computers. Mike worked on intermetallic compounds for his $\mathrm{PhD}$ (1955) and his first papers (1956) were on the structures of Al-rich ternary alloys of $\mathrm{Al}$ and $\mathrm{Cu}$, with $\mathrm{Fe}, \mathrm{Co}$ and $\mathrm{Ni}$.

W.H. Taylor had a long-standing interest in the structures of silicate minerals and this must have been at the forefront of the mind of the then Professor of Mineralogy and Petrology, C.E. Tilley, when Mike was appointed to a University Demonstratorship. Another crystallographer from the Cavendish crystallography group, Peter Gay, was also appointed as a University Demonstrator in the Department at about the same time. Their joint publications from this period, either as Gay and Bown or Bown and Gay, reflect a close collaboration based on the use of single crystal $\mathrm{X}$-ray diffraction to explore the complex structural relationships found in natural plagioclase felspars. "The reciprocal lattice geometry of the plagioclase feldspar structures" (Bown and Gay, 1958) is a definitive summary of the different structure types found in both natural and experimental samples. It has provided the language and starting point for almost all attempts to rationalise the properties and remarkable behaviour of one of the most important groups of rock-forming minerals in the Earth's crust.

Another colleague of Mike's in the Department of Mineralogy and Petrology in the 1950's, J.V. Smith, later wrote in the X-ray diffraction techniques section of his book, Feldspar Minerals vol. 1 (1974): "Highly skilled crystallographers may wish to use the oscillation technique developed by Drs. M.G. Bown and P. Gay of Cambridge University, England. A $15^{\circ}$ oscillation photograph about the c-axis allows ready identification of all the important diffraction phenomena of plagioclases. However, the preliminary identification of the c-axis and alignment of the crystal in the $X$ ray camera requires considerable skill'. One of the oscillation cameras that Mike would have used for a substantial proportion of his research is shown in Fig. 2, below. The X-ray beam came in from the right to be diffracted from a crystal mounted on a glass spindle in the middle of the cylinder. Photographic paper lining the inside of the cylinder recorded the diffracted beams and the strangely shaped cams seen at the front of the instrument were used to make the crystal oscillate through carefully chosen angles. The horizontal microscope coming from the left was used to check that the crystal would end up in the centre of the X-ray beam. Oscillation photographs of plagioclase feldspar crystals shown in Fig. 3 are copies of originals taken by Mike and Peter and used in J.V. Smith's book (Smith, 1974). Sharp eyed readers will be able to pick out the diffraction spots listed in Fig. 4, which gives the definitive description of diffraction effects in natural samples.

At the same time as he was working on plagioclase feldspars with Peter Gay, Mike started his work on pyroxenes, using 


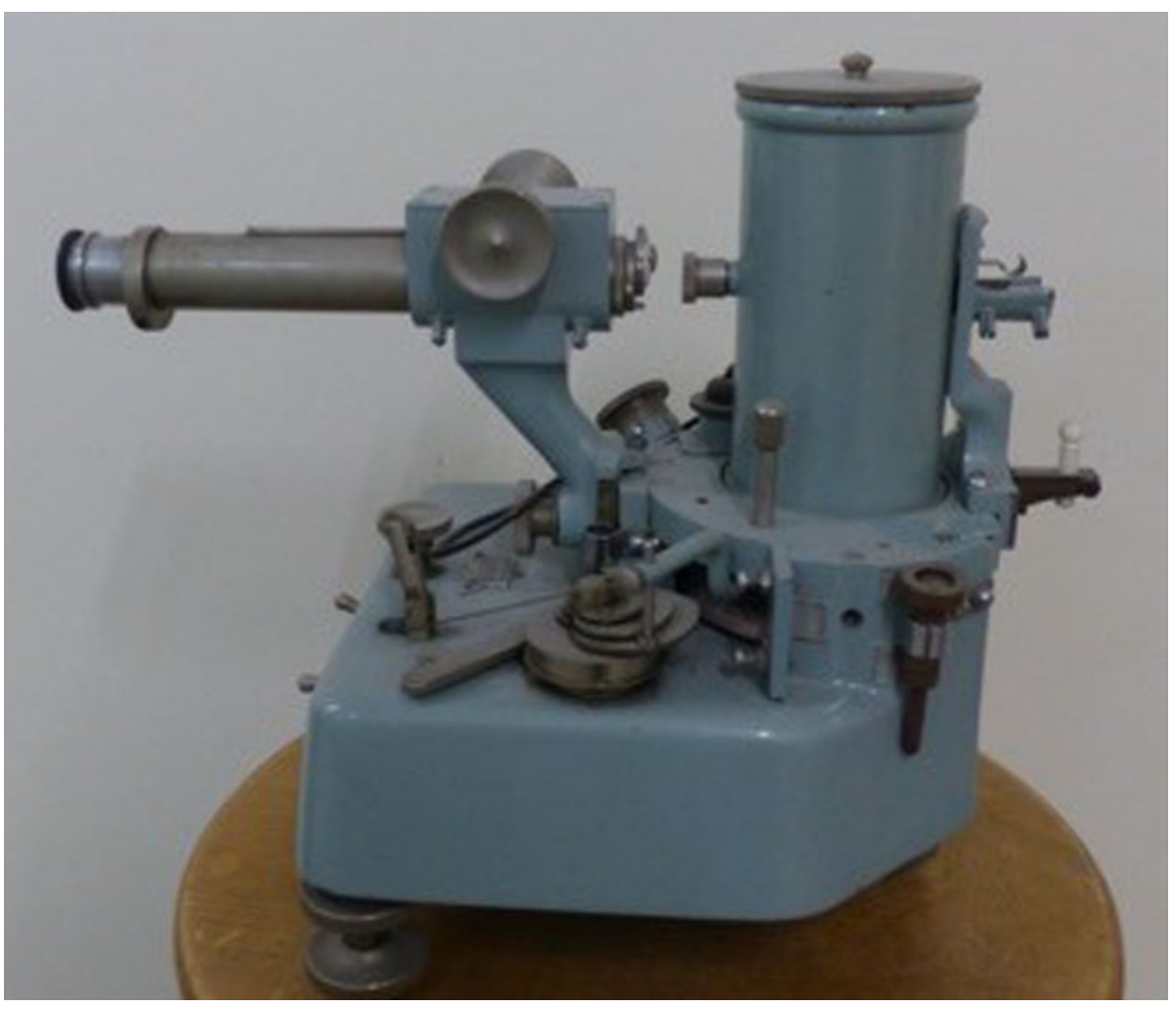

Fig. 2. A Unicam single crystal rotation and oscillation X-ray camera from the X-ray lab in the Department of Earth Sciences. It is an original instrument inherited from the Dept. of Mineralogy and Petrology. As well as being used by Mike for his research it was used for many years by students learning single crystal $\mathrm{X}$-ray techniques. single-crystal X-ray diffraction to characterise orientation relationships in crystals with exsolution textures. He must have been influenced by wider interest at the time in rocks from the Skaergaard intrusion, East Greenland, leading to another classic work based on the study of 50 crystals: "An X-ray study of exsolution phenomena in the Skaergaard pyroxenes" (Bown and Gay, 1960). Their work on pyroxenes and feldpsars presaged a worldwide explosion of interest throughout the 1960s and 1970s in the microstructures of minerals, as observed and analysed using transmission electron microscopy, with another of Mike's colleagues in the Department, Desmond McConnell, leading the way.

After two years as a Demonstrator in the Deparment of Geology and Mineralogy in Oxford, Mike returned to Cambridge to take up a Lectureship in Mineralogy and Petrology. His interests in feldspars and pyroxenes continued and he was one of the first crystallographers to examine lunar samples famously brought to Cambridge from the USA by Stuart Agrell. Although only an abstract, another memorable paper from this period was: "Deerite, Howeite and Zussmanite, three new minerals from the Franciscan of the Laytonville District, Mendocino Co., California" (Agrell, Bown and McKie, 1965) - linking the names of six British mineralogists who are fondly remembered by all who knew them.

In the same year that Mike was appointed to a University Lectureship, 1961, he was elected to a Fellowship in Clare College. He served there as a Tutor from 1965 to 1971, then as the Director of Studies for Natural Sciences, an onerous task that he was renowned for doing meticulously. He acted on the full range of college committees until he retired in 1995, and was known as the person who asked the awkward question that others were avoiding. Mike continued to play an active role in college life for a further two decades.
Mike's life was cruelly disrupted by the untimely death of his wife, Hilary, in 1973. After that, he devoted himself firstly to his family and secondly to his college and teaching. Eulogies delivered at his funeral affirmed him to have been a devoted father and grandfather, and a much-loved colleague at Clare.

The annual report of the Department of Earth Sciences for 1995-96 notes that Mike "formally retired from his University Lectureship but immediately returned to continue teaching mineralogy". This reflects perfectly the period of his life that the generations of alumni will remember when, above all, he enjoyed the company of young people. Over the years he lectured regularly to IA Natural Sciences Tripos students in 'Crystalline Materials' (a course shared with the Department of Materials Science and Metallurgy), as well as to first and second year geologists. His deep knowledge of crystallography was shared with smaller groups in specialist IB and part II courses (Crystalline State) including a definitive course on crystal physics. His cravat provided a distinctive and trademark appearance, and his many jokes occasionally strayed from political correctness. Everyone who was taught by Mike will have their own memories, most of which will involve his knowledge, his humour and his sense of fun.

Mike served and interacted with the wider mineralogical community with typical modesty and selflessness as General Secretary of the Mineralogical Society (1984-89) and as the first Secretary of the European Mineralogical Union (1988-92). He had two periods of sabbatical leave in the USA, firstly at Carbondale, Illinois (1965) and then at Virginia Polytechnic Institute, Blacksburg, Virginia (1973) where he was remembered as a fine crystallographer and friend for many years afterwards. He also spent two periods of sabbatical leave teaching mineralogy at the University of Zimbabwe in Harare. 

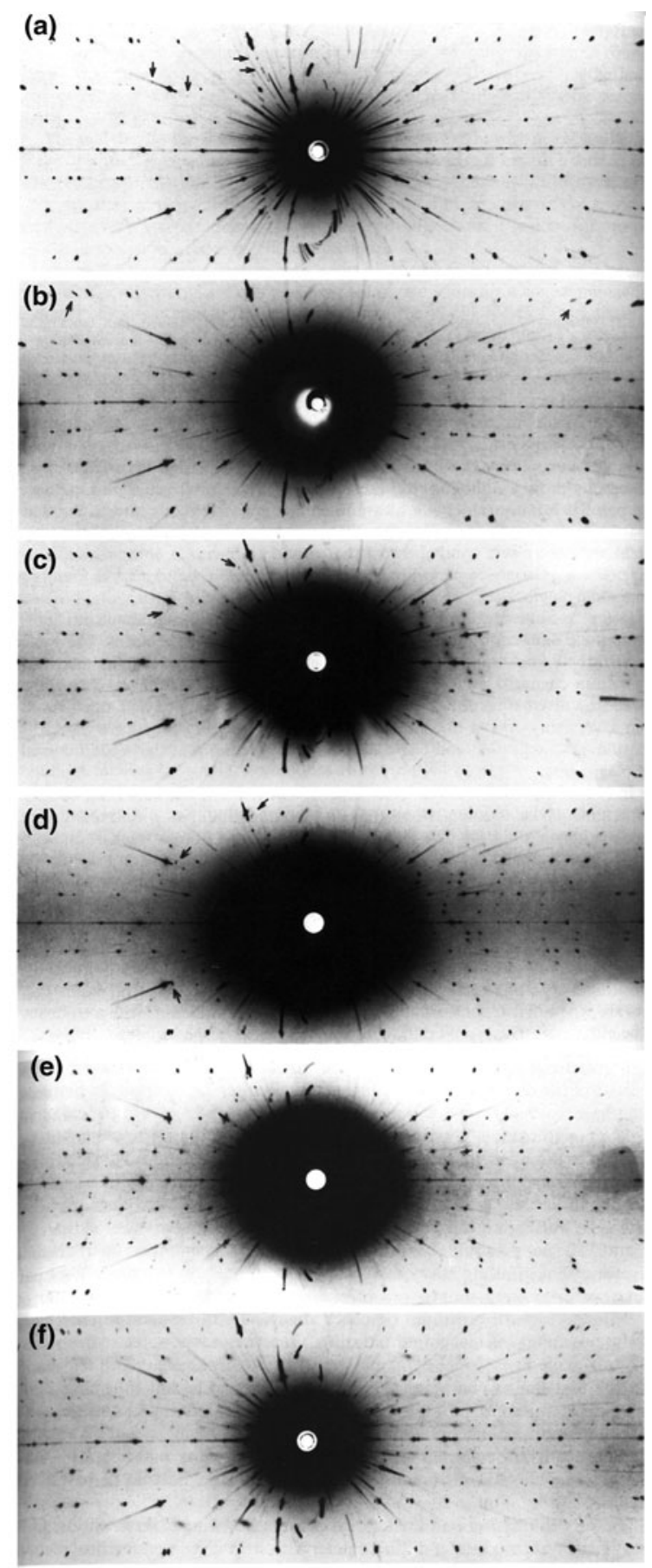

Fig. 3. Single crystal X-ray oscillation photographs of plagioclase feldspars with different compositions, taken from pages 202 and 203 of Smith (1974) from an image given to him by Bown and Gay. Details: Approximately half of each photograph is shown. $3 \mathrm{~cm}$ oscillation camera, CuK radiation. From the USA: (a) Albite from Amelia, VA; (b) peristerite $A n_{12}$ from Peekskill, NY; (c) andesine $A n_{37}$, from Yosemite Valley, CA; (d) labradorite $\mathrm{An}_{50}$, from Essex Co., NY; (e) labradorite $\mathrm{An}_{64}$, from Stillwater, MO; (f) Synthetic anorthite.

Note: Parts of this memorial are also in the University of Cambridge Clare College Review (20/21) and are reproduced here with permission.

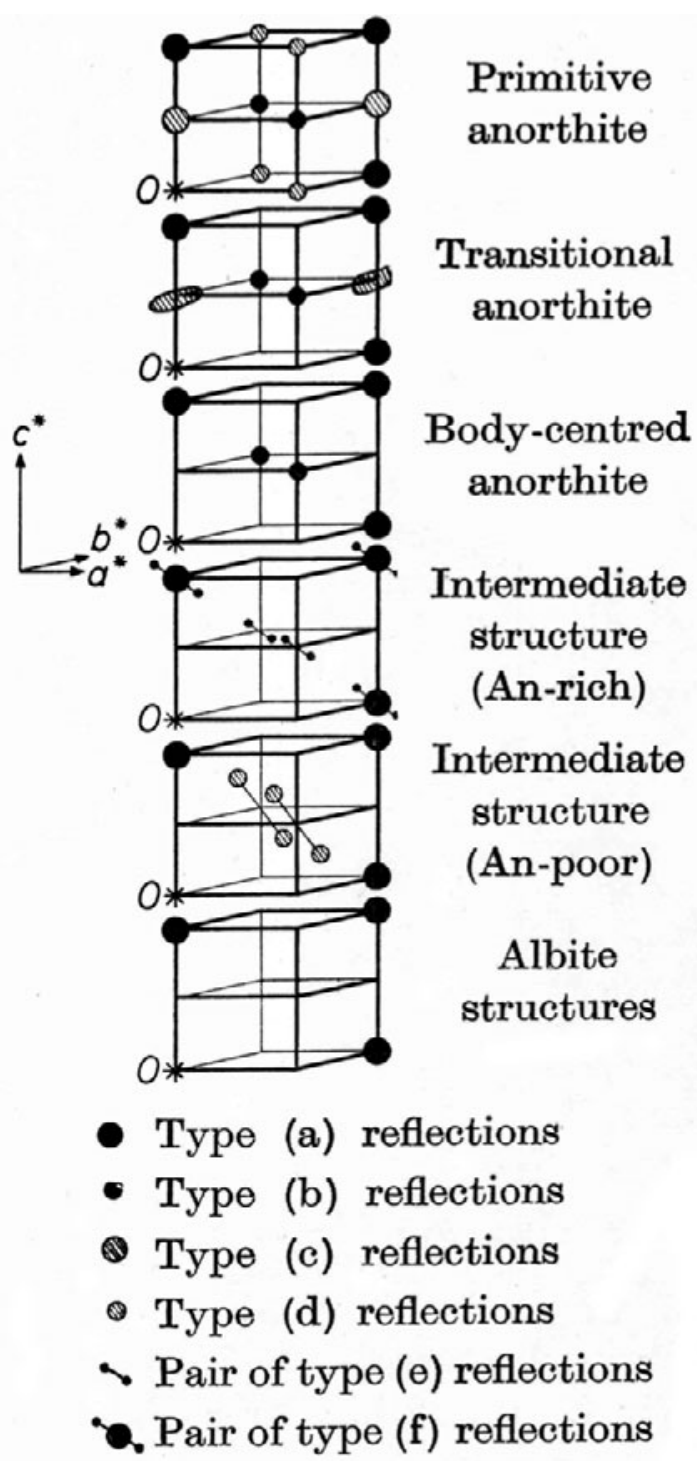

Fig. 4. This is a figure from the original, definitive paper on diffraction patterns of natural plagioclase feldspar crystals from Bown and Gay (1958). Reproduced from Bown and Gay (1958) figure 3 with permission from de Gruyter, Genthiner Str. 13. 10785 Berlin.

\section{References}

Agrell S.O., Bown M.G. and McKie D. (1965) Deerite, howieite and zussmanite, three new minerals from the Franciscan of the Laytonville District, Mendocino Co., California. American Mineralogist, 50, 278 [Abstract].

Bown M.G. and Gay P. (1958) The reciprocal lattice geometry of the plagioclase felspar structures. Zeitschrift für Kristallographie - Crystalline Materials, 111, 1-14

Bown M.G., and Gay P. (1960). An X-ray study of exsolution phenomena in the Skaergaard pyroxenes. Mineralogical Magazine and Journal of the Mineralogical Society, 32, 379-388.

Smith J.V. (1974) Feldspar Minerals. Vol. 1. Springer Nature. 